\title{
Jera IVANC $\mid$ PREVAJANJE ZA GLEDALIŠČE - DA BO VOLK SIT IN KOZA CELA. SENEKOVA MEDEJA
}

"Dalje ima tragedija neko živo izrazno moč, ki jo čutimo že ob branju, še bolj pa ob uprizoritvi.« Aristotel ${ }^{1}$

Čeprav Aristotel v svoji Poetiki uprizoritev in njeno vizualno podobo

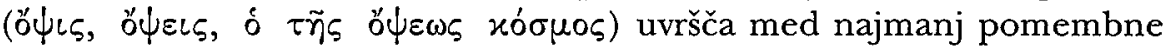
elemente tragedije, sem si vendar dovolila uporabiti zgoraj navedeno opažanje za izhodišče tega članka. Pri prevodu nekega antičnega dramskega besedila me namreč najprej zanima uprizoritev in šele nato knjižna objava. Temu botruje kar nekaj razlogov. Žalostno dejstvo je, da predvsem mladi danes vse manj berejo, sploh dramska besedila. Uprizoritev pa v nekem določenem časovnem obdobju - eno ali več gledaliških sezon, dokler trajajo ponovitve - doseže več ljudi, kot v istem obdobju neka knjižna izdaja dramskega besedila. In kot klasična filologinja si želim predvsem tega, da bi literarne stvaritve klasične Grčije in Rima dosegle čim več ljudi. Poleg tega doživimo uprizorjeno dramsko besedilo drugače, morda celo polneje, kot če ga beremo. Ne gre samo za vizualno podobo, ampak tudi za slušno. Tretji in s stališča stroke morda najtehtnejši razlog v prid uprizoritvi pa je, da so bila večinoma vsa antična dramska besedila namenjena uprizarjanju na odru. Celo tistih dramskih besedil, ki smo jih poimenovali 'bralne drame' ali z nemško ustreznejšo besedo 'Rezitationsdramen', in prvotno niso bila namenjena za uprizoritev ali pa uprizoritve niso doživela, stari niso brali tako, kot smo tega vajeni danes. Zbirali so se v večjih ali manjših skupinah, glasno brali izbrane odlomke ali pa celo prirejali javne recitacije celotnih besedil.

Dramskih besedil torej nikoli niso brali sami, potiho, v svojih naslonjačih ali za delovno mizo.

Prevajalcem antičnih del pa se nam kaj rado zgodi, da na to pozabimo. Pri svojem delu smo namreč ves čas obkroženi s knjigami, prebiramo opombe in komentarje, brskamo po leksikonih in slovarjih - brez knjig naše stroke sploh ne bi bilo. In tako se lotimo tudi prevajanja. Vsako mitološko ime, vsako neprevedljivo besedno igro, vsako aluzijo na takratne časovne dogodke opremimo s komentarji in opombami, pri tem pa pozab-

${ }^{1}$ Poetika (1462a15), prevod Kajetan Gantar, str. 97 
ljamo na prednost, ki jo ima bralec pred gledalcem. Bralec namreč lahko nerazumljive odlomke prebere večkrat, lahko obrne stran, se o mitoloških imenih pouči v opombah in komentarjih, gledalec pa te možnosti nima. Predstavljajmo si torej, kako nerazumljivo je lahko besedilo, opremljeno s takimi opombami in komentarji, povprečnemu obiskovalcu gledališča. Razlika med bralcem in gledalcem pa ni le $\mathrm{v}$ različnem doživljanju besedila in v večji ali manjši možnosti celotnejšega razumevanja takega besedila, ampak tudi v tem, da stoji med bralcem (prejemnikom) in avtorjem (pošiljateljem) le prevajalec, v gledališču pa poleg prevajalca še množica ljudi, idej in interpretacij, ki jim bom z eno besedo rekla uprizoritev. Prevajalčevo delo je v uprizoritvi najbolj vidno pri igralcu, ki govori prevajalčeve besede. Ena stvar je, če igralec ni najbolj spreten pri govoru ali interpretaciji verzov (v primeru antičnih dramskih besedil), druga stvar pa je, če prevod ni govorljiv. V prvem primeru bo morda nekdo obtožil prevajalca, v drugem primeru morda igralca. Meja je zelo tanka in zabrisana, pa vendar lahko prevajalec naredi veliko in se trudi, da prevod ne bi bil samo berljiv, ampak predvsem govorljiv. Zato bi bilo idealno, če bi prevajalec sodeloval vsaj v prvi fazi priprav uprizoritve, na bralnih vajah, in na mestih, kjer bi imeli igralci težave, upošteval njihove pripombe. Dogaja se namreč, da ima igralec na nekem mestu težave, potem pa lektor, dramaturg, morda režiser ali celo igralec sam prevod spremeni - doživela sem celo, da s primerjavo prevoda v nek drug evropski jezik -, ker pač prevajalca, ki bi bil za to najbolj pristojen, ni poleg. Prevajalec (ali stroka) ob tem morda zamahne $z$ roko češ, saj bo (ali že je) prevod objavljen tudi v knjižni obliki, gledališč je tako ali tako manj resna stvar od knjige.

Še bolj se lahko stroka zgrozi ob radikalnejših posegih v prevod ali besedilo, ki so delo dramaturga in režiserja ter v modernem gledališču popolnoma vsakdanji. Ti posegi so seveda posledica različnih dejavnikov. Lahko gre zgolj za drugačno interpretacijo dramskega besedila in koncept uprizoritve, ko na primer režiser besedila sicer ne krajša ali spreminja, a zrežira enega ali več nemih prizorov, ki lahko bistveno vplivajo na potek dramskega dogajanja ali na razumevanje odnosov med dramskimi protagonisti. Iz istih razlogov lahko režiser in dramaturg črtata daljše ali krajše odlomke, dele besedila premečeta, vanj vstavljata odlomke iz drugih dramskih besedil ali pa celo združitva dve ali več različnih besedil. Lahko črtata dele besedila, ki v modernem gledališču niso več potrebni, na primer notranje didaskalije. V antiki je bil namreč prvi 'režiser' uprizoritve praviloma avtor sam, čeprav najdemo tudi izjeme (npr.Aristofan). Igralci so dobivali napotke neposredno od njega. Obsežne zunanje didaskalije niso bile potrebne in jih zato tudi ni. Polno pa je t. i. notranjih daskalij, besedila, ki ga govorijo dramske osebe, $v$ katerem avtor napove prihode in odhode dramskih oseb, ali pa (tudi) zaradi uporabe mask opi- 
suje različna obrazna čustva svojih junakov. Besedila, ki so se ohranila do danes, torej nimajo nobenih 'režijskih' napotkov izven samega besedila razen opomb sholiastov, ki pa seveda niso avtorjeve.

Včasih pa se zgodi, da režiser in dramaturg krajše ali daljše odlomke črtata tudi zato, ker bi bili povprečnemu gledalcu nerazumljivi. To se zlahka zgodi pri takem prevodu, kjer ima prevajalec pred očmi knjižno objavo in bralca, na gledališče in gledalca pa pozablja.

Ob vsem naštetem se pojavi vprašanje zvestobe, ki je dobro znano tudi prevajalcu, le da v gledališču govorimo o zvestobi besedilu, pri prevajanju pa o zvestobi originalu. V obeh primerih gre za vprašanje zvestobe predlogi. V gledališki praksi poznamo dva ekstrema: avtonomno gledališče, ki lahko obstaja tudi popolnoma brez jezikovnega substrata, in popolno gospostvo besedila, kjer uprizoritev v besedilo ne posega. Prevajalec (in stroka) bi si seveda želel slednje. Pa vendar - kar se tiče zvestobe zunanjemu obsegu besedila - včasih že prevajalec sam, sicer minimalno, poseže v predlogo s tem, da se odloči za izdajo besedila, kjer so, na primer, verzi 541-560 postavljeni med verza 571 in 572 , kjer so verzi 803-810 črtani, ipd.

Besedila, ki so se nam ohranila do danes, namreč niso tista, ki jih je pred več ali manj kot dvema tisočletjema lastnoročno zapisal avtor, ampak so prepisi prepisov besedil, ki jih je uporabljal in pri tem črtal, popravljal ter prirejal recimo igralec ali nekdo, ki je tragedijo že dolgo po avtorjevi smrti postavil na oder. Prepisi besedila torej, ki je nastalo ob pripravljanju ene izmed repriz ${ }^{2}$. Sicer danes s primerjavami ohranjenih rokopisov lahko približno ugotovimo, katera mesta so pristna in katera ne, pa vendar. Zastavimo si rahlo izzivalno vprašanje, zgolj v premislek: Če je lahko nekdo 100, 200 ali 300 let po avtorjevi smrti ob nastajanju uprizoritve besedilu kaj dodal ali odvzel, zakaj ne bi mogel tega storiti še 500, 1000 ali 2500 let kasneje?

Zvestoba predlogi je torej v gledališču lahko zelo ohlapen pojem in po mojem mnenju o zvestobi sploh ne smemo govoriti. Kako pa je z zvestobo pri prevajanju antičnih dramskih besedil? Tudi tu sta možna dva ekstrema: prevod, ki slepo in dobesedno sledi predlogi in popolnoma prosti prevod, ki je recimo v jeziku moderniziran in v vsebini aktualiziran (na tem mestu naj samo opozorim na problem stare atiške komedije, ki zahteva čisto svojsko obravnavo). Ker je vprašanje zvestobe predlogi pri prevajanju še veliko bolj kompeksno kot $\mathrm{v}$ gledališču in bo verjetno ostalo brez enega in edino veljavnega odgovora, se bom posvetila le dvema problemoma, na katera sem naletela ob prevajanju Senekove Medeje.

${ }^{2}$ Prvič je do repriz starih tragedij v grčiji prišlo leta 386 pr. Kr., reprize pa so bile del stalnega programa v letih 341-339 pr. Kr., zelo verjetno že od leta $386 \mathrm{pr}$. Kr. naprej. Pickard-Cambridge, Wallace A., The Dramatic Festivals in Athens, Oxford, 1946, str. 100. 
Gre za problem mitoloških imen ter opisov in za problem metruma. Senekova Medeja je polna zemljepisnih, astroloških in mitoloških opisov ter imen, ki današnjemu gledalcu večinoma ne pomenijo nič, o nekaterih pa ni bil dobro poučen niti sam Seneka ${ }^{3}$. Kljub nerazumljivosti taki opisi pri uprizoritvi ne bi smeli predstavljati prevelikega problema, saj večkrat delujejo podobno kot na primer katalog imen peržanskih ljudstev in vojskovodij v prologu Ajshilovih Peržanov. Najlepši primer tega je po mojem mnenju dojiljin opis Medejinega žrtvovanja (670-639). Večji problem predstavljajo različna imena, s katerimi Seneka poimenuje dramske in druge osebe ter kraje, katerih prepoznavanje je za gledalca ključnega pomena pri razumevanju samega dramskega dejanja. Naj zapišem samo nekaj primerov: namesto Jazon stoji 'sin Ajzona', Kreuza je 'ajolska devica', Hekato imenuje zdaj 'Fojba', zdaj '(L)luna', 'Diktina', spet drugič 'hči Perzesa', Argo je 'tesalska smreka', Medejina domovina je enkrat 'Fazis', drugič 'Pont', tretjič spet 'Kolhida', Akast je 'tesalski vladar', ipd. Bo prevod še vedno zvest predlogi, če bo prevajalec na takih mestih poleg manj poznanih imen zapisal še tista bolj poznana ali pa manj poznana s slednjimi celo nadomestil? Ali naj taka mesta za uprizoritev priredi, za knjižno objavo pa ohrani in opremi z opombami in komentarji? Naj torej obstajata dva različna prevoda, eden za knjižno objavo in drugi za uprizoritev? Po mojem mnenju ne. Prevod mora biti en, razumljiv bralcu in gledalcu. Seveda pa naj prevajalec problematična mesta, kot so tista, ki sem jih omenila, za uprizoritev priredi, naj torej pri uprizoritvi tudi sodeluje.

Drugi problem, s katerim sem se spopadla in ob katerem se vedno, kadar zaide pogovor $\mathrm{v}$ to smer, krešejo mnenja nas, mlajših klasičnih filologov, je, kako prevajati grški in latinski jambski trimeter. Navada je, da ga prevajamo v blankverz in tako prevajanje zagovarjajo nekateri moji kolegi kot edino pravo. Sama sem se po tehtnem razmisleku odločila za prosti jambski verz, kjer me je omejevalo le število zlogov - od 12 do 18. Toliko zlogov ima namreč tudi Senekov jambski trimeter, saj so v latinskem jambskem trimetru dovoljene nadomestitve $\mathrm{z}$ drugimi stopicami, kar poveča število zlogov v verzu. Poleg tega je moji odločitvi botrovalo še mnogo drugih razlogov: zgoščenost latinskega jezika, izogibanje hiatu z elizijami in afajrezami, drugačen tip naglasa, kot ga pozna slovenščina, in nenazadnje tudi besedne igre, zgoščenost in dvoumnost Senekovega jezika, česar po svoji najboljši volji v slovenščini ne bi mogla približati bralcu in gledalcu v zgolj desetih ali enajstih zlogih v verzu. Tako sem se pri govornih partijah

\footnotetext{
${ }^{3}$ Na primer verz 635, 636: pobil je Herkul š Neptunovegal otroka, njega, ki podobe menja; kjer ima v mislih verjetno Periklimena, ki pa je bil v resnici Neptunov vnuk. Morda ga zamenjuje $z$ drugim Periklimenom, Neptunovim sinom in braniteljem Teb. Verz 652ss: V puščavah Libije je Idmona,/ čeprav je vedel, kaj ga čaka, kača/pustila; kača ni ubila Idmona, ampak Mopsa.
} 
odločila za prosti jamb, na mestih, kjer se mi je zdelo, da je pomembna tudi metrična oblika, pa sem se te skušala držati.

Prvi zborski spev, ki je sestavljen iz malih asklepijadejev (56-74, 93109), glikonejev (75-92) in heksametrov (110-15), sem prevedla v prostem verzu, razen zadnjega dela, kjer sem sledila metrični shemi latinskega originala.

Drugi zborski spev je sestavljen iz anapestovskih dimetrov, $v$ prevodu pa sem se odločila za amfibrahe ${ }^{4}$, katerih monotoni ritem sem mestoma uporabljala zavestno.

Tretji zborski spev je sestavljen iz sapfiških kitic. Sedem običajnih (3 sapfiški enajsterci + adonij) in sedem takih, kjer adonij sledi osmim sapfiškim enajstercem. Potem ko sem dodobra preučila vse poskuse in predloge, kako prevajati sapfiško kitico v slovenščino, sem se odločila, da sapfiške enajsterce prevedem v blankverz, adonij pa obdržim.

Četrti zborski spev je sestavljen iz katalektičnih jambskih dimetrov, $v$ prevodu pa se menjavajo katalektični in akatalektični jambski dimetri.

Metrično zelo razgiban je Medejin prizor zaklinjanja. Prvih enajst verzov (740-751) je zloženih v trohejskem tetrametru. Obdržala sem jih tudi v prevodu (akatal. in katal.)

Verzi 752-770 so zloženi v jambskem trimetru, v prevodu pa sem se odločila za blankverz.

$V$ verzih 771-86 se menjavajo jambski trimetri in jambski dimetri. Držala sem se blankverza in jambskega dimetra (katal. + akatal.).

Verzi 787-842 so zloženi v anapestovskih dimetrih, sama pa sem se tako kot v drugem zborskem spevu - odločila za amfibrahe.

V verzu 842 da Medeja poklicati otroke, njenega zaklinjanja je konec, zato spet prehajam na prosti jamb.

Prevod sem ponudila v branje svojim mlajšim in starejšim kolegom ter gledališki lektorici. Zanimiv je bil njihov popolnoma različen odziv, ki, ne glede na to, ali je moj prevod dober ali slab, priča tudi o tem, da imata stroka (klasična filologija) in gledališče na prevod različne poglede. Nekateri kolegi so se zmrdovali nad mojo izbiro prostega jamba v govornih partijah, pohvalili pa so mesta, kjer sem se skušala držati metrične sheme. Gledališka lektorica je bila ravno nasprotnega mnenja. Pohvalila je govorne partije, nekatera mesta, kjer sem se odločila za tako ali drugačno metrično obliko, pa so se ji zdela sicer krasna poezija, vendar za gledališče morda preveč podrejena obliki.

Kako naj bo torej po vsem povedanem volk sit in koza cela? Kdaj bo, če se postavim na stran gledališča, uprizoritev zadovoljna s prevodom in

\footnotetext{
${ }^{4}$ Tako prevaja grške anapeste tudi K.Gantar (prolog Ifigenije v Avlidi).
} 
kdaj bo, če govorim kot klasična filologinja, stroka zadovoljna z uprizoritvijo? Moj odgovor se glasi: volk bo sit in koza cela, ko se bo prevajalec (stroka) zavedal gledališča in ko se bo gledališče zavedalo stroke. Na tem mestu naj opomnim na razliko med profilom prevajalca dramskih besedil iz klasičnih jezikov in profilom prevajalca dramskih besedil iz modernih evropskih jezikov. Slednji znanja nekega jezika ni nujno pridobil s študijem in se $v$ mnogih primerih tudi profesionalno ukvarja $z$ gledališčem (dramatik, dramaturg...). Prvi pa je znanje ne samo jezika, ampak celotne grške in rimske kulture pridobil po dolgih letih študija in je predvsem klasični filolog, šele potem, če sploh, tudi gledališčnik. Kdo torej, če ne prav on, je najbolj poučen o Ajshilu, Sofoklu, Evripidu, Aristofanu, Menandru, Plavtu, Terenciju, Seneki, o mitoloških junakih in zgodbah, ki jih ti avtorji obdelujejo, o antični gledališki konvenciji? Tega bi se moralo zavedati gledališče in ga povabiti k sodelovanju, sam pa bi se moral zavedati pomembnosti gledališča, ki posreduje klasična dramska besedila ljudem, ter izstopiti iz visokega obzidja, s katerim se že predolgo obdaja klasična filologija.

Naslov:

Jera Ivanc

Kosovelova ulica 27

SI-1000 Ljubljana 